\title{
Remote monitoring and telemedicine in heart failure: implementation and benefits
}

\author{
Jacopo Francesco Imberti $^{1} \cdot$ Alberto Tosetti $^{1} \cdot$ Davide Antonio Mei ${ }^{1} \cdot$ Anna Maisano ${ }^{1} \cdot$ Giuseppe Boriani ${ }^{1}$
}

Accepted: 9 March 2021 / Published online: 7 May 2021

(C) The Author(s), under exclusive licence to Springer Science+Business Media, LLC, part of Springer Nature 2021

\begin{abstract}
Purpose of review Remote monitoring (RM) of cardiac implantable electronic devices (CIEDs) is recommended as part of the individualized multidisciplinary follow-up of heart failure (HF) patients. Aim of this article is to critically review recent findings on RM, highlighting potential benefits and barriers to its implementation.

Recent findings Device-based RM is useful in the early detection of CIEDs technical issues and cardiac arrhythmias. Moreover, RM allows the continuous monitoring of several patients' clinical parameters associated with impending HF decompensation, but there is still uncertainty regarding its effectiveness in reducing mortality and hospitalizations.

Summary Implementation of RM strategies, together with a proactive physicians' attitude towards clinical actions in response to RM data reception, will make RM a more valuable tool, potentially leading to better outcomes.
\end{abstract}

Keywords Remote monitoring $\cdot$ Telemedicine $\cdot$ Heart failure $\cdot$ pacemaker $\cdot$ Implantable cardioverter defibrillator $\cdot$ Cardiac resynchronization device

\section{Introduction}

Heart failure (HF) is a highly prevalent cardiovascular (CV) disease affecting approximately $1-2 \%$ of the adult population in developed countries [1-3]. Due to a high rate of morbidity and mortality, it imposes a remarkable economic burden on healthcare systems. A growing number of cardiac implantable electronic devices (CIEDs) are used to treat bradyarrhythmias and

This article is part of the Topical Collection on Myocardial Disease

Giuseppe Boriani

giuseppe.boriani@unimore.it

Jacopo Francesco Imberti

jacopo.imberti@hotmail.it

Alberto Tosetti

albertotosetti1@gmail.com

Davide Antonio Mei

davide.mei93@gmail.com

Anna Maisano

annamaisano1991@gmail.com

1 Cardiology Division, Department of Biomedical, Metabolic and Neural Sciences, University of Modena and Reggio Emilia, Policlinico di Modena, Modena, Italy tachyarrhythmias in HF patients and in a subset of appropriately selected patients to correct electrical and mechanical dyssynchrony through biventricular pacing [4, 5••, 6-8]. Many modern CIEDs harbor remote monitoring (RM) systems which can gather, store, and transmit to hospitals/clinicians data regarding the status of the device itself and a multitude of clinical parameters while the patient is at home [9]. These include early recognition of device-related malfunctions, detection of arrhythmias, heart and respiratory rate statistics and, in some cases, heart souds, intrathoracic impedance, and early sign and symptoms of $\operatorname{HF}[10,11]$, potentially leading to a timely clinical action. Thus, RM has joined in-person evaluation in the follow-up of HF patients. Nevertheless, despite the undoubted potential benefits, robust data showing an improvement of outcomes in patients followed-up with RM as compared with inoffice only evaluations are scant.

Aim of this article is to critically review recent data on RM of CIEDs in HF patients, highlighting potential benefits and barriers to its implementation. The evaluation of the effects of other types of RM, namely, structured telephone support, telemedicine, and remote monitoring with implanted monitoring-only devices, is outside the object of this review. 


\section{Detection of CIEDs-related complications}

Device-based RM has a well-established role beside in-person office visits in the early detection of CIEDs technical issues [12-16]. Moreover, it is useful to reduce the incidence of inappropriate ICD shocks. The number of system-related complications per year (including lead complications and generator malfunctions) is not negligible [17-20] and their prompt identification can improve patients' management. In the TRUST trial, 1339 ICD patients were randomized in a 2:1 fashion to RM with daily transmissions or to conventional care with office visits only. During the 15th month followup, RM detected generator and lead problems earlier than conventional care (median of 1 vs. 5 days respectively; $p=$ 0.05 ) [13]. RM proved also safe and useful in reducing total in-hospital device evaluations [11] and demonstrated robust transmission reliability (91\%) without reducing battery longevity [21]. Recently, Watanabe et al. [22•] studied 1274 consecutive patients implanted with a PM randomized to RM only or in-office follow-up (2 visits per year). After 24 months, RM only follow-up did not increase the occurrence of death, stroke, or cardiovascular events requiring surgery ( $10.9 \%$ vs. $11.8 \%$, respectively, $p<0.01$ for noninferiority) suggesting that RM is safe and able to reduce resource consumption. Device and lead advisories represent a major concern for the physician and for the patient as well. Despite rare [23], device malfunctions can be life-threatening and, on the other hand, replacement of the generator/leads before an overt malfunction may expose the patient to unnecessary risks [24, $25]$ as well as an organizational burden and costs for hospitals and the health care system [26]. Guédon-Moreau et al. [14] reported a $7.5 \%$ lead dysfunction rate in 40 recipients of a high-voltage lead prone to fracture, remotely followed for 22 \pm 4 months. In a retrospective cohort of patients with ICD lead fractures, RM sent alert messages in $91 \%$ of all lead-related ICD complications [27]. In this setting, RM offers a double benefit: (1) provides an immediate detection of abnormal device behavior through a continuous surveillance of several parameters such as lead impedance and sensing and (2) avoids too early device replacements.

\section{Detection and management of cardiac arrhythmias}

CIEDs can record, analyze, and store different types of atrial and ventricular arrhythmias through one or more intracavitary catheters. The continuous monitoring of atrial activity can identify arrhythmic episodes characterized by high atrial rate (AHREs) in asymptomatic patients with no history of clinical atrial fibrillation $(\mathrm{AF})$. These episodes, common in patients necessitating CIEDs, include different forms of atrial tachyarrhythmias such as atrial tachycardias, atrial flutter and AF
[28]. AHREs are associated with a considerable risk of adverse clinical events including death [29], hospitalizations [30, 31], stroke/systemic thromboembolism [32-34], occurrence of heart failure [35], and progression to clinical AF [36]. In 2012, 2580 patients with no history of AF were enrolled in the prospective ASSERT [32] trial and were followed for a mean of 2.5 years. AHREs were associated with a 2.5 -fold $(95 \% \mathrm{CI}$ 1.28-4.89) higher risk of stroke or systemic embolism at the multivariate analysis. These findings were later confirmed in large observational studies [37-39] and meta-analysis [40]. It also emerged that the higher the burden of AHREs, the higher the risk of future thromboembolic events [41]. RM proved successful in the early identification of AHREs and may reduce the time to potentially meaningful clinical decision such as the institution of an oral anticoagulant therapy, which offers huge and well-established benefits in patients with clinical AF and, presumably, also in selected patients with AHREs [11, 41-46]. Ricci et al. [47] conducted a Monte Carlo simulation showing that in patients with AHREs daily RM may reduce the stroke risk with respect to standard in-person visits scheduled every 6 to 12 months, but ad hoc studies are needed to demonstrate the possible clinical benefits of RM in this setting. In a subanalysis of the ASSERT trial [31], AHREs progression to episodes lasting more than $24 \mathrm{~h}$ or to clinical AF was independently associated with HF hospitalization (HR 4.58; 95\% CI 1.6-12.8). Therefore, a timely identification of AHREs and of their progression to a higher AF burden or to clinical AF has the potential to improve the outcome of HF patients [36, 48]. Finally, ICDs have a well-recognized lifesaving role [49-52], but inappropriate ICD shocks are fearful and common events associated with increased mortality [53]. In the THORN registry [54] (a large RM database of 1882 ICD patients), a $9 \%$ prevalence of inappropriate ventricular arrhythmia detection and a $3 \%$ prevalence of inappropriate shocks over $13.7 \pm 3.4$ months of follow-up was reported. In a substudy of the ECOST trial [55], during 27 months followup, $5 \%$ of patients in the RM group received 1 or more inappropriate shocks versus $10.4 \%$ in the control group, suggesting that RM can be effective in the prevention of inappropriate ICD shocks.

\section{Heart failure: a major public health threat}

The prevalence of chronic HF (1-2\% of the adult population in developed countries) is expected to increase with ageing population [1-3]. Over the last decades, new treatments improved patients outcomes, but morbidity, mortality, and hospitalization rates remain still high [56]. Acute exacerbations of HF often require prolonged in-hospital treatments and also contribute to disease progression and adverse prognosis. Thirty days all-cause readmission rate reaches up to 20\% [57] and 10 -year mortality approaches 99\% [58]. Hospitalizations are 
at the center of the high cost of HF care accounting for approximately $70 \%$ of the global costs [59]. Therefore, huge efforts should address this unmet need. The vast majority of HF readmissions are due to fluid overload [60] and the process of decompensation starts weeks before the acute event through subtle hemodynamic changes which can be detected by some RM systems [61]. A persistent increase in filling pressures in response to small augmentation in intravascular volume is the first measurable event that can be observed. Shortly after, autonomic adaptation through sympathetic activation and vagal withdrawal intervene to increase cardiac output. Heart rate variability is a physiologic parameter that can be measured by CIEDs and directly relates to the autonomic control of the heart: the lower the heart rate variability, the higher the sympathetic tone. One study found that heart rate variability was lower in unstable patients at risk for hospitalization and changes could have been seen 16 to 20 days before symptoms of worsening heart failure with a $70 \%$ sensitivity [62]. The next pathophysiologic step is progression to pulmonary circulation congestion, which can be detected by changes in intrathoracic impedance about 2 weeks before hospitalization [63]. Weight changes ( $>2$ pounds in 24-36 h) occur approximately 7 days before hospitalization but, although specific (97\%), this is not a sensitive (9\%) nor an early marker [64]. Several studies failed to demonstrate that weight gain alone is valuable for HF management $[65,66]$. Finally, symptoms develop in the last phase of this process, just before the hospitalization [61].

\section{Remote monitoring of heart failure patients}

RM aims to respond to the unmet need of HF hospitalizations and deaths prevention and it is recommended as part of a multidisciplinary approach to the management of HF patients [5, 67] (Fig. 1). Among the multiple parameters that can be continuously or frequently assessed, many commercially available CIEDs allow also the measurement of intrathoracic impedance, which is inversely correlated with pulmonary capillary wedge pressure and fluid balance. A decrease in intrathoracic impedance precedes and predicts patient symptoms and hospital admissions [63, 68-71]. In 2011, van Veldhuisen et al. [72] randomized 335 chronic HF patients implanted with an ICD/CRTD featuring a monitoring tool capable of tracking changes in intrathoracic impedance in two groups. In the access arm physicians received RM information in case of preset threshold crossings, while in the control arm they did not. During $14.9 \pm 5.4$ months of follow-up, $29 \%$ of patients in the access arm and $20 \%$ of patients in the control arm reached the composite endpoint of all-cause mortality and HF hospitalizations (HR 1.52; 95\% CI 0.97-2.37), showing that the use of the monitoring tool was not beneficial. Additional algorithms incorporating multiple HF related indexes such as thoracic impedance, heart sounds (S1, S3), respiratory rate and relative tidal volume, activity response and heart rate have been developed to overcome the limited efficacy of single parameters [73]. In the study by Boehmer et al. [10], the device-based diagnostic algorithm combining these indexes showed $70 \%$ sensitivity in predicting impending HF decompensation. The reported 34 days median time between the alert and the HF events is potentially valuable to establish an early therapy and the 1.47 per patient-year unexplained alert rate is acceptable. Clinical usefulness of this algorithm will be clarified in upcoming clinical trials (MANAGE-HF, NCT03237858 and PREEMPT-HF, NCT 03579641) targeted to assess if decision making based on the information provided by these algorithms may result in significant changes in hospitalization burden and cardiovascular mortality as compared to standard clinical judgment. More recently, in a cohort of $918 \mathrm{ICD} / \mathrm{CRTD}$ patients, D'Onofrio et al. combined the Seattle Heart Failure Score with the temporal trends of specific individual device-based variables to test an index capable of predicting the first HF hospitalization post-implant. Preliminary data show a $73.3 \%$ sensitivity, with low false alert rate [74]. Similarly, in 2010, the TRUST randomized controlled trial (RCT) showed that RM was safe and allowed an early detection of actionable events (defined as an event that prompted initiation/up-titration of antiarrhythmic medications or significant ICD reprogramming/system revision) compared with standard care [11], but this advantage failed to translate into a clinical benefit in most of the following RCTs (Table 1). In the MORE-CARE prospective, multicenter, randomized controlled trial, 865 CRTD patients were randomized to RM checks alternating with in-office follow-up or in-office followup only. No significant difference was found in the primary endpoint (a composite of death and cardiovascular and devicerelated hospitalization) between the 2 groups (HR 1.02; 95\% CI 0.80-1.30). However, the authors found a significant $38 \%$ reduction in the use of healthcare resources (i.e., 2-year rates of CV hospitalizations, CV emergency department admissions, CV in-office follow-up) in favor of the RM group, mainly as a result of a decrease in in-office visits [84]. A total of $1650 \mathrm{HF}$ patients implanted with a CIED (ICD, CRTD or CRTP) were randomly assigned to active RM or to usual care in the REM-HF randomized controlled trial. RM consisted of weekly transmissions in the active arm and also transmissions every 6 months in the usual care arm, but in the latter group, they were not used to manage HF in any form. After a median of 2.8 years follow-up, no significant differences were observed between the 2 arms in the composite endpoint of allcause death or CV hospitalizations (HR 1.01; 95\% CI 0.871.18 ) or in its individual components. The authors concluded that RM strategy provided no benefit over usual care for patients with HF [85•]. A considerable proportion of patient (38\% at 24 months) transmitted data for $<75 \%$ of the weeks. Beside this gap in achiveing a comprehensive monitoring, 


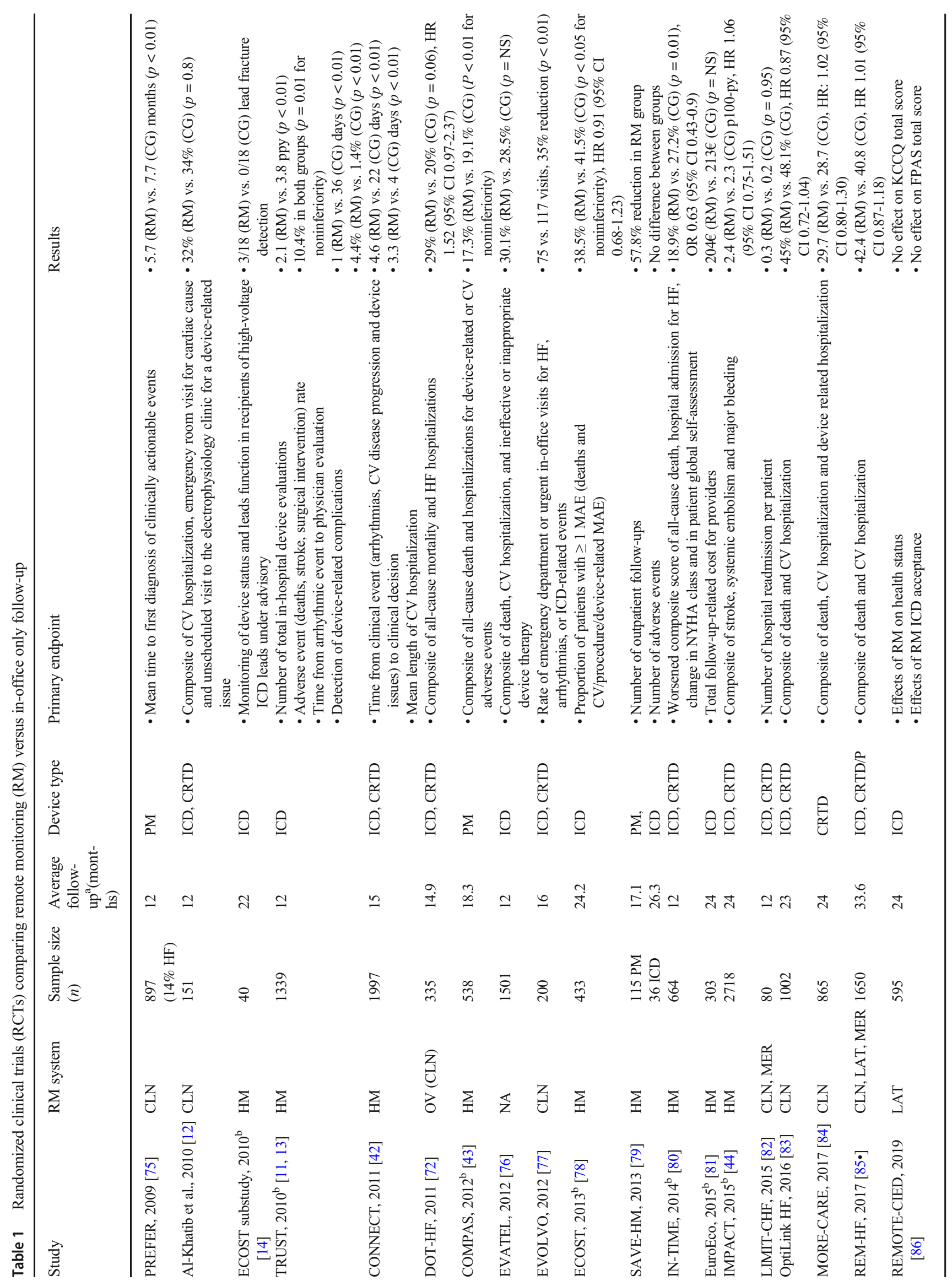




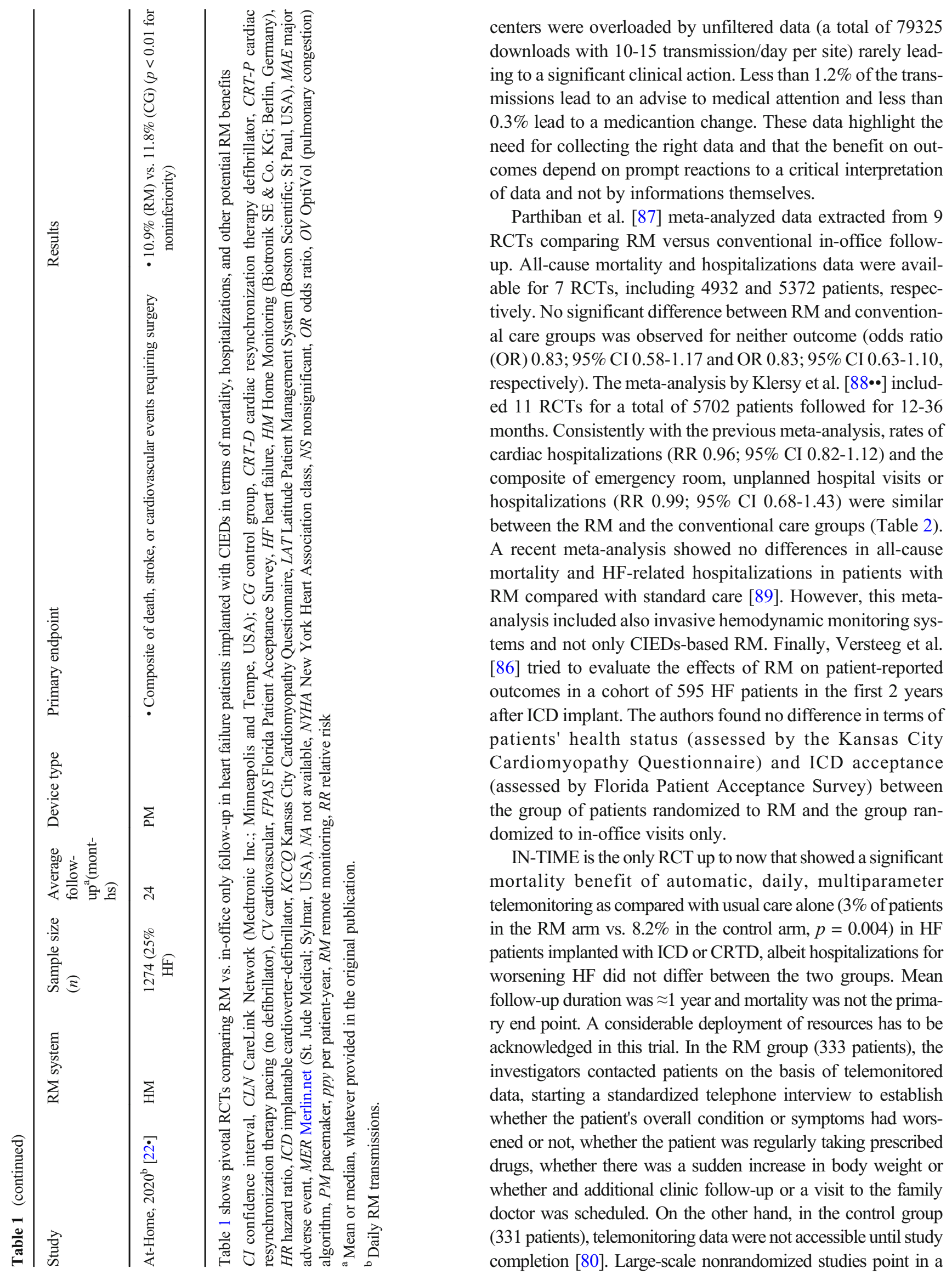


Fig. 1. Remote monitoring as part the multidisciplinary approach to the treatment of heart failure patients. CIEDs cardiac implantable electronic devices, $E P$ electrophysiology, $H F$ heart failure

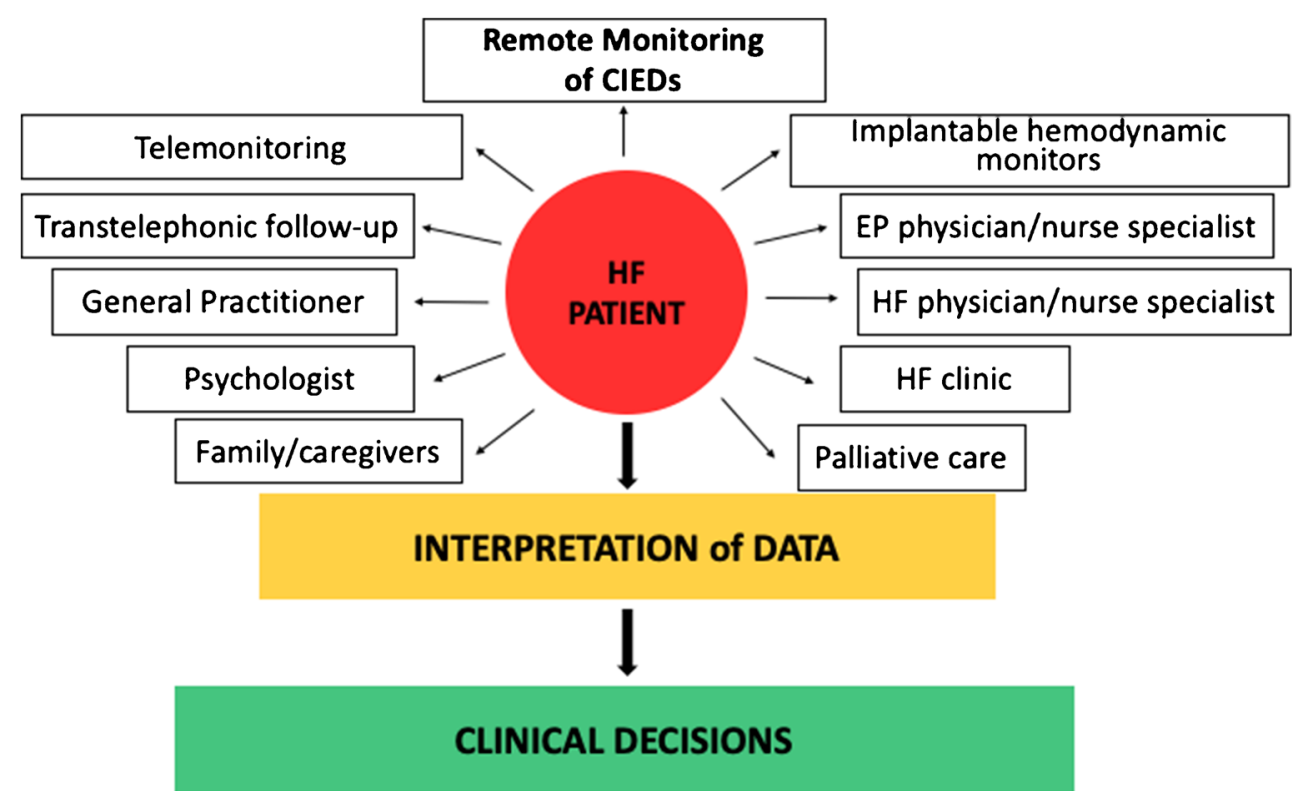

similar direction, showing a survival advantage for patients undergoing RM as compared with those receiving in-person only follow-up [90-92]. However, given the nonrandomized design of these studies, several biases may have affected the results and their generalizability, thus requiring caution in data interpretation.

In recent years, the possibility that daily RM transmissions may increase data processing capacity leading to higher sensitivity and specificity as compared with weekly transmissions has been investigated. Hindricks et al. [93] performed a pooled patient-level meta-analysis of 3 RCTs (TRUST, ECOST, IN-TIME) using the Home Monitoring system that is based on daily verification of transmissions. The authors reported a $1.9 \%(p=0.037)$ reduction in the absolute risk of all-cause death at 1 year in the RM group and a $5.6 \%(p=$
0.007) reduction in the composite endpoint of all-cause mortality or hospitalization for worsening HF. The latter analysis was conducted including only 2 trials (ECOST, IN-TIME). Daily transmission of data is an alternative approach as compared to RM systems transmitting preset alerts activated at specific predefined thresholds. In the absence of direct comparisons between these 2 approaches, the superiority of daily RM remains speculative and should be tested towards clinical outcomes at long-term in dedicated randomized trials.

Altogether, these data indicate that RM of CIEDs represents a valuable tool in the early diagnosis of $\mathrm{HF}$ decompensation, but its effectiveness in reducing mortality and hospitalizations is still uncertain. They anyway suggest that implementation of RM can be a worth doing strategy, especially in consideration of the impact

Table 2 Meta-analysis of randomized clinical trials on remote monitoring of cardiac implantable electronic devices from various device manufacturers: effects on mortality, hospitalizations, and visits

\begin{tabular}{|c|c|c|c|c|c|c|}
\hline Meta-analysis & RM system & Sample size $(n)$ & $\begin{array}{l}\text { Average } \\
\text { follow-up }^{\text {a }} \\
\text { (Months) }\end{array}$ & No of studies included & Primary endpoint & Results \\
\hline $\begin{array}{l}\text { Parthiban et al. } \\
\text { (2015) [87] }\end{array}$ & $\mathrm{HM}, \mathrm{CLN}$ & $\begin{array}{l}4932 \\
5372\end{array}$ & $\begin{array}{l}14.4 \\
\mathrm{NA}\end{array}$ & $\begin{array}{l}7 \\
7\end{array}$ & $\begin{array}{l}\text { - All-cause mortality (RM vs. CG) } \\
\text { - Hospitalizations (RM vs. CG) }\end{array}$ & $\begin{array}{l}\text { - OR } 0.83 \text { (95\% CI } 0.58-1.17) \\
\text { - OR } 0.83 \text { (95\% CI } 0.63-1.10)\end{array}$ \\
\hline $\begin{array}{l}\text { Klersy et al., } \\
\quad(2016)[88 \bullet \bullet]\end{array}$ & HM, CLN & 5702 & $12-36$ & 11 & $\begin{array}{l}\text { - Reduction in total number of } \\
\text { visits (RM vs. CG) } \\
\text { - Cardiac hospitalizations } \\
\text { (RM vs. CG) } \\
\text { - Composite of emergency room, } \\
\text { unplanned hospital visits, or } \\
\text { hospitalizations (RM vs. CG) }\end{array}$ & $\begin{array}{l}\text { - RR } 0.56 \text { (95\% CI } 0.43-0.73) \\
\text { - RR } 0.96 \text { (95\% CI } 0.82-1.12) \\
\text { - RR } 0.99 \text { (95\% CI } 0.68-1.43)\end{array}$ \\
\hline
\end{tabular}

CI confidence interval, $C L N$ CareLink Network (Medtronic Inc.; Minneapolis and Tempe, USA), CG control group, HM Home Monitoring (Biotronik $\mathrm{SE} \&$ Co. KG; Berlin, Germany), No number, $N A$ not available, $O R$ odds ratio, $R M$, remote monitoring, RR, relative risk

${ }^{a}$ Mean or median, whatever provided in the original publication 
of COVID-19 pandemic [94, 95] with need for more accurate analysis in the next future.

\section{Progresses and pitfalls in everyday implementation of remote monitoring}

The use of RM has markedly increased in recent years, as shown by the comparison of two Italian surveys conducted in 2012 and 2017 [96]. The global COVID-19 pandemic is further boosting the RM implementation in order to keep social-distancing to the utmost [95]. However, RM is still largely underused in clinical practice [92]. Barriers to its implementation are mainly the lack of reimbursement, need for significant changes in hospitals' workflows, data overload, and increased workload for health-care providers [97-101]. The growing bunch of clinical evidence on the safety and usefulness of RM, combined with the overcoming of the reimbursement issue, will probably lead to a wider overall adoption of this valuable tool, which will obviously will markedly benefit from active involvement of general practitioners, caregivers, and empowered patients [102].

\section{Conclusions}

$\mathrm{RM}$ is recommended for the early detection of CIEDs technical issues and early diagnosis and management of cardiac arrhythmias [5, 67]. In recent years, multiparameter RM has gained relevance in the individualized management of HF patients implanted with a CIED. Despite good sensitivity in predicting worsening $\mathrm{HF}$, the role of RM in improving patients' outcome is still matter of debate. Factors that may lead to a more profitable use of RM include a better selection of parameters to monitor and patients to candidate to RM and a more proactive attitude towards disease management of $\mathrm{HF}$, with an appropriate organization of care strictly linking hospital care to home care. A paradigm shift from remote patient monitoring to remote patient management is warranted, translating data into prompt clinical actions.

\section{Compliance with ethical standards}

Conflict of interest Dr. Boriani has received small speaker's fees from Medtronic, Boston, Biotronik, Boehringer, and Bayer outside of the submitted work. The other authors report no conflict of interest.

Consent for publication This article does not contain any studies with human or animal subjects performed by any of the authors.

\section{References}

Papers of particular interest, published recently, have been highlighted as:

- Of importance

- Of major importance

1. Ceia F, Fonseca C, Mota T, Morais H, Matias F, de Sousa A, et al. Prevalence of chronic heart failure in Southwestern Europe: the EPICA study. Eur J Heart Fail. 2002;4(4):531-9.

2. Bleumink GS, Knetsch AM, Sturkenboom MC, Straus SM, Hofman A, Deckers JW, et al. Quantifying the heart failure epidemic: prevalence, incidence rate, lifetime risk and prognosis of heart failure The Rotterdam Study. Eur Heart J. 2004;25(18):1614-9.

3. Redfield MM, Jacobsen SJ, Burnett JC, Mahoney DW, Bailey KR, Rodeheffer RJ. Burden of systolic and diastolic ventricular dysfunction in the community: appreciating the scope of the heart failure epidemic. JAMA. 2003;289(2):194-202.

4. Mond HG, Proclemer A. The 11th world survey of cardiac pacing and implantable cardioverter-defibrillators: calendar year 2009-a World Society of Arrhythmia's project. Pacing Clin Electrophysiol. 2011;34(8):1013-27.

5.• Ponikowski P, Voors AA, Anker SD, Bueno H, Cleland JGF, Coats AJS, et al. 2016 ESC Guidelines for the diagnosis and treatment of acute and chronic heart failure: The Task Force for the diagnosis and treatment of acute and chronic heart failure of the European Society of Cardiology (ESC)Developed with the special contribution of the Heart Failure Association (HFA) of the ESC. Eur Heart J. 2016;37(27):2129-200 Current ESC Guidelines for the diagnosis and treatment of acute and chronic heart failure.

6. Boriani G, Berti E, Belotti LM, Biffi M, De Palma R, Malavasi VL, et al. Cardiac device therapy in patients with left ventricular dysfunction and heart failure: 'real-world' data on long-term outcomes (mortality, hospitalizations, days alive and out of hospital). Eur J Heart Fail. 2016;18(6):693-702.

7. Boriani G, Ziacchi M, Nesti M, Battista A, Placentino F, Malavasi VL, et al. Cardiac resynchronization therapy: How did consensus guidelines from Europe and the United States evolve in the last 15 years? Int J Cardiol. 2018;261:119-29.

8. Mullens W, Auricchio A, Martens P, Witte K, Cowie MR, Delgado V, et al. Optimized Implementation of cardiac resynchronization therapy: a call for action for referral and optimization of care: A joint position statement from the Heart Failure Association (HFA), European Heart Rhythm Association (EHRA), and European Association of Cardiovascular Imaging (EACVI) of the European Society of Cardiology. Eur J Heart Fail. 2020;22(12):2349-69. https://doi.org/10.1002/ejhf.2046.

9. Boriani G, Diemberger I, Martignani C, Biffi M, Valzania C, Bertini $\mathrm{M}$, et al. Telecardiology and remote monitoring of implanted electrical devices: the potential for fresh clinical care perspectives. J Gen Intern Med. 2008;23(Suppl 1):73-7.

10. Boehmer JP, Hariharan R, Devecchi FG, Smith AL, Molon G, Capucci A, et al. A Multisensor Algorithm Predicts Heart Failure Events in Patients With Implanted Devices: Results From the MultiSENSE Study. JACC Heart Fail. 2017;5(3):216-25.

11. Varma N, Epstein AE, Irimpen A, Schweikert R, Love C, Investigators T. Efficacy and safety of automatic remote monitoring for implantable cardioverter-defibrillator follow-up: the Lumos-T Safely Reduces Routine Office Device Follow-up (TRUST) trial. Circulation. 2010;122(4):325-32.

12. Al-Khatib SM, Piccini JP, Knight D, Stewart M, Clapp-Channing N, Sanders GD. Remote monitoring of implantable cardioverter defibrillators versus quarterly device interrogations in clinic: 
results from a randomized pilot clinical trial. J Cardiovasc Electrophysiol. 2010;21(5):545-50.

13. Varma N, Michalski J, Epstein AE, Schweikert R. Automatic remote monitoring of implantable cardioverter-defibrillator lead and generator performance: the Lumos-T Safely RedUceS RouTine Office Device Follow-Up (TRUST) trial. Circ Arrhythm Electrophysiol. 2010;3(5):428-36.

14. Guédon-Moreau L, Chevalier P, Marquié C, Kouakam C, Klug D, Lacroix D, et al. Contributions of remote monitoring to the followup of implantable cardioverter-defibrillator leads under advisory. Eur Heart J. 2010;31(18):2246-52.

15. Nielsen JC, Kottkamp H, Zabel M, Aliot E, Kreutzer U, Bauer A, et al. Automatic home monitoring of implantable cardioverter defibrillators. Europace. 2008;10(6):729-35.

16. Folino AF, Chiusso F, Zanotto G, Vaccari D, Gasparini G, Megna A, et al. Management of alert messages in the remote monitoring of implantable cardioverter defibrillators and pacemakers: an Italian single-region study. Europace. 2011;13(9):1281-91.

17. Ranasinghe I, Parzynski CS, Freeman JV, Dreyer RP, Ross JS, Akar JG, et al. Long-Term Risk for Device-Related Complications and Reoperations After Implantable Cardioverter-Defibrillator Implantation: An Observational Cohort Study. Ann Intern Med. 2016;165(1):20-9.

18. Hawkins NM, Grubisic M, Andrade JG, Huang F, Ding L, Gao M, et al. Long-term complications, reoperations and survival following cardioverter-defibrillator implant. Heart. 2018;104(3):237-43.

19. Eckstein J, Koller MT, Zabel M, Kalusche D, Schaer BA, Osswald S, et al. Necessity for surgical revision of defibrillator leads implanted long-term: causes and management. Circulation. 2008;117(21):2727-33.

20. van Rees JB, van Welsenes GH, Borleffs CJ, Thijssen J, van der Velde ET, van der Wall EE, et al. Update on small-diameter implantable cardioverter-defibrillator leads performance. Pacing Clin Electrophysiol. 2012;35(6):652-8.

21. Varma N, Love CJ, Schweikert R, Moll P, Michalski J, Epstein AE, et al. Automatic remote monitoring utilizing daily transmissions: transmission reliability and implantable cardioverter defibrillator battery longevity in the TRUST trial. Europace. 2018;20(4):622-8.

22. Watanabe E, Yamazaki F, Goto T, Asai T, Yamamoto T, Hirooka $\mathrm{K}$, et al. Remote Management of Pacemaker Patients With Biennial In-Clinic Evaluation: Continuous Home Monitoring in the Japanese At-Home Study: A Randomized Clinical Trial. Circ Arrhythm Electrophysiol. 2020;13(5):e007734 Recent RCT showing that replacing periodic in-office follow-up with RM follow-up in pacemaker.

23. Perrotta L, Pieragnoli P, Ricciardi G, Sacchi S, Mascia G, Padeletti M, et al. Multicenter experience with implantable defibrillators subject to recall. Pacing Clin Electrophysiol. 2011;34(8):998-1002.

24. Gould PA, Krahn AD, Advisories CHRSWGoD. Complications associated with implantable cardioverter-defibrillator replacement in response to device advisories. JAMA. 2006;295(16):1907-1911.

25. Boriani G, Merino J, Wright DJ, Gadler F, Schaer B, Landolina M. Battery longevity of implantable cardioverter-defibrillators and cardiac resynchronization therapy defibrillators: technical, clinical and economic aspects. An expert review paper from EHRA. Europace. 2018;20(12):1882-97.

26. Palmisano P, Ziacchi M, Belotti G, Rapacciuolo A, Santini L, Stabile $\mathrm{G}$, et al. Clinical and organizational management of cardiac implantable electronic device replacements: an Italian Survey promoted by AIAC (Italian Association of Arrhythmology and Cardiac Pacing). J Cardiovasc Med (Hagerstown). 2019;20(8):531-41.

27. Spencker S, Coban N, Koch L, Schirdewan A, Müller D. Potential role of home monitoring to reduce inappropriate shocks in im- plantable cardioverter-defibrillator patients due to lead failure. Europace. 2009;11(4):483-8.

28. Gorenek B, Bax J, Boriani G, Chen SA, Dagres N, Glotzer TV, et al. Device-detected subclinical atrial tachyarrhythmias: definition, implications and management-an European Heart Rhythm Association (EHRA) consensus document, endorsed by Heart Rhythm Society (HRS), Asia Pacific Heart Rhythm Society (APHRS) and Sociedad Latinoamericana de Estimulación Cardíaca y Electrofisiología (SOLEACE). Europace. 2017;19(9):1556-78.

29. Gonzalez M, Keating RJ, Markowitz SM, Liu CF, Thomas G, Ip JE, et al. Newly detected atrial high rate episodes predict longterm mortality outcomes in patients with permanent pacemakers. Heart Rhythm. 2014;11(12):2214-21.

30. Pastori D, Miyazawa K, Li Y, Székely O, Shahid F, Farcomeni A, et al. Atrial high-rate episodes and risk of major adverse cardiovascular events in patients with cardiac implantable electronic devices. Clin Res Cardiol. 2020;109(1):96-102.

31. Wong JA, Conen D, Van Gelder IC, McIntyre WF, Crijns HJ, Wang J, et al. Progression of Device-Detected Subclinical Atrial Fibrillation and the Risk of Heart Failure. J Am Coll Cardiol. 2018;71(23):2603-11.

32. Healey JS, Connolly SJ, Gold MR, Israel CW, Van Gelder IC, Capucci A, et al. Subclinical atrial fibrillation and the risk of stroke. N Engl J Med. 2012;366(2):120-9.

33. Glotzer TV, Daoud EG, Wyse DG, Singer DE, Ezekowitz MD, Hilker C, et al. The relationship between daily atrial tachyarrhythmia burden from implantable device diagnostics and stroke risk: the TRENDS study. Circ Arrhythm Electrophysiol. 2009;2(5): 474-80.

34. Glotzer TV, Hellkamp AS, Zimmerman J, Sweeney MO, Yee R, Marinchak R, et al. Atrial high rate episodes detected by pacemaker diagnostics predict death and stroke: report of the Atrial Diagnostics Ancillary Study of the MOde Selection Trial (MOST). Circulation. 2003;107(12):1614-9.

35. Khan AA, Boriani G, Lip GYH. Are atrial high rate episodes (AHREs) a precursor to atrial fibrillation? Clin Res Cardiol. 2020;109(4):409-16.

36. Boriani G, Glotzer TV, Ziegler PD, De Melis M, Mangoni di S Stefano L, Sepsi M, et al. Detection of new atrial fibrillation in patients with cardiac implanted electronic devices and factors associated with transition to higher device-detected atrial fibrillation burden. Heart Rhythm. 2018;15(3):376-83.

37. Boriani G, Glotzer TV, Santini M, West TM, De Melis M, Sepsi $\mathrm{M}$, et al. Device-detected atrial fibrillation and risk for stroke: an analysis of $>10,000$ patients from the SOS AF project (Stroke preventiOn Strategies based on Atrial Fibrillation information from implanted devices). Eur Heart J. 2014;35(8):508-16.

38. Turakhia MP, Ziegler PD, Schmitt SK, Chang Y, Fan J, Than CT, et al. Atrial Fibrillation Burden and Short-Term Risk of Stroke: Case-Crossover Analysis of Continuously Recorded Heart Rhythm From Cardiac Electronic Implanted Devices. Circ Arrhythm Electrophysiol. 2015;8(5):1040-7.

39. Kaplan RM, Koehler J, Ziegler PD, Sarkar S, Zweibel S, Passman RS. Stroke Risk as a Function of Atrial Fibrillation Duration and CHA. Circulation. 2019;140(20):1639-46.

40. Mahajan R, Perera T, Elliott AD, Twomey DJ, Kumar S, Munwar DA, et al. Subclinical device-detected atrial fibrillation and stroke risk: a systematic review and meta-analysis. Eur Heart J. 2018;39(16):1407-15.

41. Hindricks G, Potpara T, Dagres N, Arbelo E, Bax JJ, BlomströmLundqvist $\mathrm{C}$, et al. ESC Guidelines for the diagnosis and management of atrial fibrillation developed in collaboration with the European Association of Cardio-Thoracic Surgery (EACTS). Eur Heart J. 2020:ehaa612. 
42. Crossley GH, Boyle A, Vitense H, Chang Y, Mead RH, Investigators $\mathrm{C}$. The CONNECT (Clinical Evaluation of Remote Notification to Reduce Time to Clinical Decision) trial: the value of wireless remote monitoring with automatic clinician alerts. J Am Coll Cardiol. 2011;57(10):1181-9.

43. Mabo P, Victor F, Bazin P, Ahres S, Babuty D, Da Costa A, et al. A randomized trial of long-term remote monitoring of pacemaker recipients (the COMPAS trial). Eur Heart J. 2012 May;33(9):1105-11.

44. Martin DT, Bersohn MM, Waldo AL, Wathen MS, Choucair WK, Lip GY, et al. Randomized trial of atrial arrhythmia monitoring to guide anticoagulation in patients with implanted defibrillator and cardiac resynchronization devices. Eur Heart J. 2015;36(26):1660-8.

45. Ricci RP, Vaccari D, Morichelli L, Zanotto G, Calò L, D'Onofrio A, et al. Stroke incidence in patients with cardiac implantable electronic devices remotely controlled with automatic alerts of atrial fibrillation. A sub-analysis of the HomeGuide study. Int J Cardiol. 2016;219:251-6.

46. Boriani G, Healey JS, Schnabel RB, Lopes RD, Calkins H, Camm JA, et al. Oral anticoagulation for subclinical atrial tachyarrhythmias detected by implantable cardiac devices: an international survey of the AF-SCREEN Group. Int J Cardiol. 2019;296:65-70.

47. Ricci RP, Morichelli L, Gargaro A, Laudadio MT, Santini M. Home monitoring in patients with implantable cardiac devices: is there a potential reduction of stroke risk? Results from a computer model tested through monte carlo simulations. J Cardiovasc Electrophysiol. 2009;20(11):1244-51.

48. Boriani $\mathrm{G}$, Vitolo M. Atrial fibrillation in patients with cardiac implantable electronic devices: new perspectives with important clinical implications. Kardiol Pol. 2019;77(12):1119-20.

49. Investigators AIDA. A comparison of antiarrhythmic-drug therapy with implantable defibrillators in patients resuscitated from near-fatal ventricular arrhythmias. N Engl J Med. 1997;337(22): 1576-83.

50. Kadish A, Dyer A, Daubert JP, Quigg R, Estes NA, Anderson KP, et al. Prophylactic defibrillator implantation in patients with nonischemic dilated cardiomyopathy. N Engl J Med. 2004;350(21):2151-8

51. Moss AJ, Zareba W, Hall WJ, Klein H, Wilber DJ, Cannom DS, et al. Prophylactic implantation of a defibrillator in patients with myocardial infarction and reduced ejection fraction. $\mathrm{N}$ Engl $\mathrm{J}$ Med. 2002;346(12):877-83.

52. Boriani G, Malavasi VL. Extending survival by reducing sudden death with implantable cardioverter-defibrillators: a challenging clinical issue in non-ischaemic and ischaemic cardiomyopathies. Eur J Heart Fail. 2018;20(3):420-6.

53. Proietti R, Labos C, Davis M, Thanassoulis G, Santangeli P, Russo V, et al. A systematic review and meta-analysis of the association between implantable cardioverter-defibrillator shocks and long-term mortality. Can J Cardiol. 2015;31(3):270-7.

54. Perrin T, Boveda S, Defaye P, Rosier A, Sadoul N, Bordachar P, et al. Role of medical reaction in management of inappropriate ventricular arrhythmia diagnosis: the inappropriate Therapy and HOme monitoRiNg (THORN) registry. Europace. 2019;21(4):607-15.

55. Guédon-Moreau L, Kouakam C, Klug D, Marquié C, Brigadeau F, Boulé S, et al. Decreased delivery of inappropriate shocks achieved by remote monitoring of ICD: a substudy of the ECOST trial. J Cardiovasc Electrophysiol. 2014;25(7):763-70.

56. Maggioni AP, Dahlström U, Filippatos G, Chioncel O, Crespo Leiro M, Drozdz J, et al. EURObservational Research Programme: regional differences and 1-year follow-up results of the Heart Failure Pilot Survey (ESC-HF Pilot). Eur J Heart Fail. 2013;15(7):808-17.

57. Bergethon KE, Ju C, DeVore AD, Hardy NC, Fonarow GC, Yancy $\mathrm{CW}$, et al. Trends in 30-day readmission rates for patients hospitalized with heart failure: findings from the get with the guidelines-heart failure registry. Circ Heart Fail. 2016;9(6).

58. Chun S, Tu JV, Wijeysundera HC, Austin PC, Wang X, Levy D, et al. Lifetime analysis of hospitalizations and survival of patients newly admitted with heart failure. Circ Heart Fail. 2012;5(4):414-21.

59. Dickstein K, Cohen-Solal A, Filippatos G, McMurray JJ, Ponikowski P, Poole-Wilson PA, et al. ESC Guidelines for the diagnosis and treatment of acute and chronic heart failure 2008: the Task Force for the Diagnosis and Treatment of Acute and Chronic Heart Failure 2008 of the European Society of Cardiology. Developed in collaboration with the Heart Failure Association of the ESC (HFA) and endorsed by the European Society of Intensive Care Medicine (ESICM). Eur Heart J. 2008;29(19):2388-442.

60. Fonarow GC, Abraham WT, Albert NM, Stough WG, Gheorghiade M, Greenberg BH, et al. Factors identified as precipitating hospital admissions for heart failure and clinical outcomes: findings from OPTIMIZE-HF. Arch Intern Med. 2008;168(8):847-54.

61. Adamson PB. Pathophysiology of the transition from chronic compensated and acute decompensated heart failure: new insights from continuous monitoring devices. Curr Heart Fail Rep. 2009;6(4):287-92.

62. Adamson PB, Kleckner KJ, VanHout WL, Srinivasan S, Abraham WT. Cardiac resynchronization therapy improves heart rate variability in patients with symptomatic heart failure. Circulation. 2003;108(3):266-9.

63. Yu CM, Wang L, Chau E, Chan RH, Kong SL, Tang MO, et al. Intrathoracic impedance monitoring in patients with heart failure: correlation with fluid status and feasibility of early warning preceding hospitalization. Circulation. 2005;112(6):841-8.

64. Chaudhry SI, Wang Y, Concato J, Gill TM, Krumholz HM. Patterns of weight change preceding hospitalization for heart failure. Circulation. 2007;116(14):1549-54.

65. Zhang J, Goode KM, Cuddihy PE, Cleland JG, Investigators T-H. Predicting hospitalization due to worsening heart failure using daily weight measurement: analysis of the Trans-European Network-Home-Care Management System (TEN-HMS) study. Eur J Heart Fail. 2009;11(4):420-7.

66. Lyngå P, Persson H, Hägg-Martinell A, Hägglund E, Hagerman I, Langius-Eklöf A, et al. Weight monitoring in patients with severe heart failure (WISH). A randomized controlled trial. Eur J Heart Fail. 2012;14(4):438-44.

67. Slotwiner D, Varma N, Akar JG, Annas G, Beardsall M, Fogel RI, et al. HRS Expert Consensus Statement on remote interrogation and monitoring for cardiovascular implantable electronic devices. Heart Rhythm. 2015;12(7):e69-100.

68. Small RS, Wickemeyer W, Germany R, Hoppe B, Andrulli J, Brady PA, et al. Changes in intrathoracic impedance are associated with subsequent risk of hospitalizations for acute decompensated heart failure: clinical utility of implanted device monitoring without a patient alert. J Card Fail. 2009;15(6):475-81.

69. Vanderheyden M, Houben R, Verstreken S, Ståhlberg M, Reiters $\mathrm{P}$, Kessels R, et al. Continuous monitoring of intrathoracic impedance and right ventricular pressures in patients with heart failure. Circ Heart Fail. 2010;3(3):370-7.

70. Whellan DJ, Ousdigian KT, Al-Khatib SM, Pu W, Sarkar S, Porter CB, et al. Combined heart failure device diagnostics identify patients at higher risk of subsequent heart failure hospitalizations: results from PARTNERS HF (Program to Access and Review Trending Information and Evaluate Correlation to Symptoms in Patients With Heart Failure) study. J Am Coll Cardiol. 2010;55(17):1803-10. 
71. Cowie MR, Sarkar S, Koehler J, Whellan DJ, Crossley GH, Tang $\mathrm{WH}$, et al. Development and validation of an integrated diagnostic algorithm derived from parameters monitored in implantable devices for identifying patients at risk for heart failure hospitalization in an ambulatory setting. Eur Heart J. 2013;34(31):2472-80.

72. van Veldhuisen DJ, Braunschweig F, Conraads V, Ford I, Cowie MR, Jondeau G, et al. Intrathoracic impedance monitoring, audible patient alerts, and outcome in patients with heart failure. Circulation. 2011;124(16):1719-26.

73. Kotalczyk A, Kalarus Z, Wright DJ, Boriani G, Lip GYH. Cardiac Electronic Devices: Future Directions and Challenges. Med Devices (Auckl). 2020;13:325-38.

74. D'Onofrio A, Solimene F, Calò L, Calvi V. Combining home monitoring temporal trends and baseline patient risk profile for predicting impending heart failure hospitalizations. Results from the SELENE HF (BIO.Detect HF IV) study. Eur Heart J. 2020:1551.

75. Crossley GH, Chen J, Choucair W, Cohen TJ, Gohn DC, Johnson WB, et al. Clinical benefits of remote versus transtelephonic monitoring of implanted pacemakers. J Am Coll Cardiol. 2009;54(22): 2012-9.

76. Mabo P, Defaye P, Sadoul N. Remote follow-up of patients implanted with an ICD: the prospective randomized Evatel study (abstr). Heart Rhythm. 2012:S226-S7.

77. Landolina M, Perego GB, Lunati M, Curnis A, Guenzati G, Vicentini A, et al. Remote monitoring reduces healthcare use and improves quality of care in heart failure patients with implantable defibrillators: the evolution of management strategies of heart failure patients with implantable defibrillators (EVOLVO) study. Circulation. 2012;125(24):2985-92.

78. Guédon-Moreau L, Lacroix D, Sadoul N, Clémenty J, Kouakam C, Hermida JS, et al. A randomized study of remote follow-up of implantable cardioverter defibrillators: safety and efficacy report of the ECOST trial. Eur Heart J. 2013;34(8):605-14.

79. Perl S, Stiegler P, Rotman B, Prenner G, Lercher P, Anelli-Monti M, et al. Socio-economic effects and cost saving potential of remote patient monitoring (SAVE-HM trial). Int J Cardiol. 2013;169(6): $402-7$.

80. Hindricks G, Taborsky M, Glikson M, Heinrich U, Schumacher B, Katz A, et al. Implant-based multiparameter telemonitoring of patients with heart failure (IN-TIME): a randomised controlled trial. Lancet. 2014;384(9943):583-90.

81. Heidbuchel H, Hindricks G, Broadhurst P, Van Erven L, Fernandez-Lozano I, Rivero-Ayerza M, et al. EuroEco (European Health Economic Trial on Home Monitoring in ICD Patients): a provider perspective in five European countries on costs and net financial impact of follow-up with or without remote monitoring. Eur Heart J. 2015;36(3):158-69.

82. Domenichini G, Rahneva T, Diab IG, Dhillon OS, Campbell NG, Finlay MC, et al. The lung impedance monitoring in treatment of chronic heart failure (the LIMIT-CHF study). Europace. 2016;18(3): 428-35.

83. Böhm M, Drexler H, Oswald H, Rybak K, Bosch R, Butter C, et al. Fluid status telemedicine alerts for heart failure: a randomized controlled trial. Eur Heart J. 2016;37(41):3154-63.

84. Boriani G, Da Costa A, Quesada A, Ricci RP, Favale S, Boscolo $\mathrm{G}$, et al. Effects of remote monitoring on clinical outcomes and use of healthcare resources in heart failure patients with biventricular defibrillators: results of the MORE-CARE multicentre randomized controlled trial. Eur J Heart Fail. 2017;19(3):416-25.

85. Morgan JM, Kitt S, Gill J, McComb JM, Ng GA, Raftery J, et al. Remote management of heart failure using implantable electronic devices. Eur Heart J. 2017;38(30):2352-60 The largest RCT performed sofar, showing no significant effects of RM on outcomes.
86. Versteeg H, Timmermans I, Widdershoven J, Kimman GJ, Prevot $\mathrm{S}$, Rauwolf T, et al. Effect of remote monitoring on patientreported outcomes in European heart failure patients with an implantable cardioverter-defibrillator: primary results of the REMOTE-CIED randomized trial. Europace. 2019;21(9):1360-8.

87. Parthiban N, Esterman A, Mahajan R, Twomey DJ, Pathak RK, Lau DH, et al. Remote Monitoring of Implantable CardioverterDefibrillators: A Systematic Review and Meta-Analysis of Clinical Outcomes. J Am Coll Cardiol. 2015;65(24):2591-600.

88.• Klersy C, Boriani G, De Silvestri A, Mairesse GH, Braunschweig F, Scotti V, et al. Effect of telemonitoring of cardiac implantable electronic devices on healthcare utilization: a meta-analysis of randomized controlled trials in patients with heart failure. Eur J Heart Fail. 2016;18(2):195-204 A meta-analysis of 11 RCTs showing no benefits of RM over standard care in terms of rates.

89. Alotaibi S, Hernandez-Montfort J, Ali OE, El-Chilali K, Perez $\mathrm{BA}$. Remote monitoring of implantable cardiac devices in heart failure patients: a systematic review and meta-analysis of randomized controlled trials. Heart Fail Rev. 2020;25(3):469-79.

90. Saxon LA, Hayes DL, Gilliam FR, Heidenreich PA, Day J, Seth $\mathrm{M}$, et al. Long-term outcome after ICD and CRT implantation and influence of remote device follow-up: the ALTITUDE survival study. Circulation. 2010;122(23):2359-67.

91. Akar JG, Bao H, Jones PW, Wang Y, Varosy PD, Masoudi FA, et al. Use of remote monitoring is associated with lower risk of adverse outcomes among patients with implanted cardiac defibrillators. Circ Arrhythm Electrophysiol. 2015;8(5):1173-80.

92. Varma N, Piccini JP, Snell J, Fischer A, Dalal N, Mittal S. The relationship between level of adherence to automatic wireless remote monitoring and survival in pacemaker and defibrillator patients. J Am Coll Cardiol. 2015;65(24):2601-10.

93. Hindricks G, Varma N, Kacet S, Lewalter T, Søgaard P, GuédonMoreau L, et al. Daily remote monitoring of implantable cardioverter-defibrillators: insights from the pooled patient-level data from three randomized controlled trials (IN-TIME, ECOST, TRUST). Eur Heart J. 2017;38(22):1749-55.

94. Mattioli AV, Cossarizza A, Boriani G. COVID-19 pandemic: usefulness of telemedicine in management of arrhythmias in elderly people. J Geriatr Cardiol. 2020;17(9):593-6.

95. Boriani G, Palmisano P, Guerra F, Bertini M, Zanotto G, Lavalle C, et al. Impact of COVID-19 pandemic on the clinical activities related to arrhythmias and electrophysiology in Italy: results of a survey promoted by AIAC (Italian Association of Arrhythmology and Cardiac Pacing). Intern Emerg Med. 2020;15(8):1445-56.

96. Palmisano P, Melissano D, Zanotto G, Perego GB, Toselli T, Landolina $\mathrm{M}$, et al. Change in the use of remote monitoring of cardiac implantable electronic devices in Italian clinical practice over a 5-year period: results of two surveys promoted by the AIAC (Italian Association of Arrhythmology and Cardiac Pacing). J Cardiovasc Med (Hagerstown). 2020;21(4):305-14.

97. Braunschweig F, Anker SD, Proff J, Varma N. Remote monitoring of implantable cardioverter-defibrillators and resynchronization devices to improve patient outcomes: dead end or way ahead? Europace. 2019;21(6):846-55.

98. Zanotto G, Melissano D, Baccillieri S, Campana A, Caravati F, Maines M, et al. Intrahospital organizational model of remote monitoring data sharing, for a global management of patients with cardiac implantable electronic devices: a document of the Italian Association of Arrhythmology and Cardiac Pacing. J Cardiovasc Med (Hagerstown). 2020;21(3):171-81.

99. Boriani G, Imberti JF, Vitolo M. Atrial fibrillation and remote monitoring through cardiac implantable electronic devices in heart failure patients. Eur J Heart Fail. 2020;22(3):554-6. 
100. Maines M, Tomasi G, Moggio P, Peruzza F, Catanzariti D, Angheben $\mathrm{C}$, et al. Implementation of remote follow-up of cardiac implantable electronic devices in clinical practice: organizational implications and resource consumption. J Cardiovasc Med (Hagerstown). 2020;21(9):648-53.

101. Boriani G. Remote monitoring of cardiac implantable electrical devices in Europe: quo vadis? Europace. 2015;17(5):674-6.
102. Padula MS, D'Ambrosio GG, Tocci M, D'Amico R, Banchelli F, Angeli L, et al. Home care for heart failure: can caregiver education prevent hospital admissions? A randomized trial in primary care. J Cardiovasc Med (Hagerstown). 2019;20(1):30-8.

Publisher's Note Springer Nature remains neutral with regard to jurisdictional claims in published maps and institutional affiliations. 